\title{
Design Capabilities Development in A Malaysian Automotive Vendor Company
}

\author{
Ana Sakura Zainal Abidin, Rasli Muslimen, Shahrol \\ Mohamaddan \\ Department of Mechanical and Manufacturing Engineering \\ UNIMAS \\ Sarawak, Malaysia
}

\begin{abstract}
Global competition has made manufacturing enhancement saturated. Manufacturers have to find new ways of increasing their competitiveness. A company's capability to conduct design determines the success of innovative products as a main determinant of profit attainment, especially in the technological industry. Design capability (DC) is defined as the availability of technical manpower skills and facilities to conduct design, namely, $R \& D$, testing equipment and prototyping facilities, and the presence of technology to support current and future manufacturing innovations. DC is a company unique resource and can be deployed as a strategy to response in any circumstances and enable a company to anticipate future market demands and to manage global challenges. However, not many Malaysian automotive vendors have full in-house DC. Prior studies also found that Malaysian vendors have limited capabilities in finance, technology and facilities which have impeded the DC development. There is a number of critical success factors (CSFs) involved in developing successful DC. Currently, studies on vendors DC, particularly in Malaysia are very limited, making the development process more complicated. A study was conducted in an automotive vendor company that has successfully developed an in-house DC and was able to improve its business performance. Productivity, reputation and the company's competitive advantage were increased. Thus, the DC development of the company was studied and a framework was proposed. This study is to enable other vendor companies to emulate and understand the DC requirements and serve as a guide for other companies intending to develop their DC.
\end{abstract}

Keywords-Design Capability (DC), Malaysia, automotive vendor, CSFs

\section{INTRODUCTION}

Global competition has made manufacturing enhancement saturated. Manufacturers have to find new ways of increasing their competitiveness. Nowadays, excellence in manufacturing alone is inadequate for a company to lead in the consumerdriven market. Intens5.e competition from the global market, demanding customers, critical resources, and environmental

\author{
Rosnah Mohd Yusuff, Noorul Amni Qistina Mohd \\ Daud \\ Department of Mechanical and Manufacturing Engineering \\ UPM \\ Selangor, Malaysia
}

issues have put manufacturers in a tough situation. The situation has pushed manufacturers to improve productivity beyond the typical practice. Enhancing company's design capability (DC) can be the smartest solution as it offers a very wide potential for products improvement and can be strategic differentiator because it has greater influence on customerdefined value as well as investment and cost compared with manufacturing ability, which is limited to quality and productivity [1], [2], [3], [4], [5], [6]. The Toyota Production System (TPS), through its basic philosophy of eliminating waste, has successfully sparked revolution in the automotive industry. At present, the idea is expanding beyond the manufacturing line, moving upstream toward efficient PD. Efficient PD considers the total value stream of the process thoroughly. Most of the important decisions regarding products are decided in advance during the PD process to improve both design and manufacturing stages. Greater flexibility in PD enables design changes with minimum impact because failures or defects can be removed earlier before reaching the production line [5].

Company's capability to conduct design determines the success of product development (PD), which is very important as a main determinant of profit attainment, especially in high technology industry [7]. In the automotive industry, the process of innovation and PD are very important and at the forefront as compared to other manufacturing industries [8]. Building a car is more complicated than building other consumer products because of more than 20000 parts involved [4]. Automakers cannot develop products on their own. As based on conservative PD practice, the process took 24 to 30 months to complete one new car model. Indeed, Toyota manages to bring a new model to start of production in just 15 months [1]. As compared to conservative $\mathrm{PD}$, the design responsibility was solely put on automaker. As of now, concurrent engineering enables automakers to conduct new PD activities with the assistance of hundreds of vendors at once. For example, Toyota works with 150 to 300 vendors [9] and Proton works with 265 vendors (as of February, 2010). In order to support the strategy, the vendors' roles becoming more severe and also need to be equipped with sufficient level of DC to ensure the success of the strategy.

This paper presented the outcomes of a study on DC development in Malaysian automotive vendor specifically 